\title{
Pengaruh Asuhan Keperawatan Terhadap Konsep Kesehatan dan Keselamatan Kerja ( K3 ) di Rumah Sakit
}

\author{
Cindy Minannisa
}

\section{cindyminannisa01@gmail.com}

\begin{abstract}
Abstrak
Dari waktu ke waktu keberadaan institusi rumah sakit semakin dituntut untuk memberikan pelayanan prima dalam bidang kesehatan kepada masyarakat. Dalam pelayanan kesehatan, para perawat diharapkan juga dapat memberikan pelayanan secara berkualitas. Perawat sebagai tenaga kesehatan yang profesional dan merupakan tenaga kesehatan terbesar yang ada di rumah sakit mempunyai peranan yang sangat penting dalam mewujudkan keselamatan pasien. K3 adalah upaya yang bertujuan untuk meningkatkan dan memelihara derajat kesehatan fisik, mental dan sosial yang setinggi-tingginya bagi pekerja di semua jenis pekerjaan, pencegahan terhadap gangguan kesehatan pekerja yang disebabkan oleh kondisi pekerjaan; perlindungan bagi pekerja dalam pekerjaannya dari risiko akibat faktor yang merugikan kesehatan. . Tujuan: untuk mengetahui peran perawat dalam menjaga keselamatan pasien di ruang rawat inap dan menjaga kesehatan dan keselamatan bekerja di rumah sakit. Metode: Tugas ini menggunakan metode kualitatif dan analisis dari berbagai jurnal yang berhubungan dengan pengetahuna asuhan keperawatan dalam menjaga keselamatan dan kesehatan kerja pasien dan perawat. Hasil: perawat mengetahui konsep dasar kesehatan dan keselamatan kerja ( K3 ).
\end{abstract}

\section{Kata Kunci: Kesehatan, Keselamatan, Bahaya, Resiko}

\section{Latar Belakang}

Pelayanan keperawatan yang berkualitas menjadi faktor penentu tingkat kepuasan pasien. Pelayanan keperawatan yang diberikan semakin baik akan meningkatkan kepuasan pasien (Cahyadi \& Mudayana, 2014; Wulandari, 2015). Pelayanan keperawatan sebagai lini terdepan berperan sangat tinggi atas kepuasan yang diterima pasien (Philip, 2014).

Sistem model asuhan keperawatan professional (MAKP) adalah suatu kerangka kerja yang mendefinisikan empat unsur yakni standar, proses keperawatan, pendidikan keperawatan, 
sistem MAKP. Perawat profesional dalam memberikan pelayanan keperawatan di masa depan adalah harus dapat berkomunikasi secara lengkap, adekuat dan cepat (Nursalam, 2012). Pelayanan keperawatan akan lebih memuaskan tentunya dengan penerapan model asuhan keperawatan professional karena kepuasan pasien ditentukan salah satunya dengan pelayanan keperawatan yang optimal (Fisbach, 1991 dalam jurnal Nur Hidayah, 2014).

Asuhan keperawatan adalah suatu pendekatan untuk pemecahan masalah pada pasien dengan memberikan pelayanan keperawatan. Proses asuhan keperawatan merupakan tugas dan kewajiban seorang perawat dari pasien datang sampai pasien pulang, dimulai dengan pengkajian secara menyeluruh, kemudian menegakkan diagnosa keperawatan dari data pengkajian tersebut, serta melaksanakan intervensi, implementasi dan evaluasi keefektifan diagnosa awal yang sudah ditegakkan (Nursalam, 2007).

Dalam Undang-Undang Nomor 23 Tahun 1992 tentang Kesehatan, Pasal 23 dinyatakan bahwa upaya Kesehatan dan Keselamatan Kena (K3) harus diselenggarakan di semua tempat kerja, khususnya tempat kerja yang mempunyai risiko bahaya kesehatan. Jika diperhatikan pasal di atas maka jelaslah bahwa Rumah Sakit (RS) termasuk dalam kriteria tempat kerja dengan berbagai ancaman bahaya yang berdampak kepada kesehatan, tidak hanya terhadap para pelaku langsung yang bekerja di RS, tapi juga terhadap pasien maupun pengunjung RS. Sehingga seharusnya pihak pengelola RS menerapkan upaya-upaya K3 di RS.

K3 merupakan aspek yang penting dalam usaha meningkatkan kesejahteraan karyawan. Apabila tingkat keselamatan kerja tinggi, maka kecelakaan yang menyebabkan sakit, cacat, dan kematian dapat ditekan sekecil mungkin. Kesehatan dan keselamatan kerja merupakan upaya untuk memberikan jaminan keselamatan dan meningkatkan derajat kesehatan para pekerja/ pemberi layanan kesehatan khususnya perawat dengan cara pencegahan kecelakaan dan penyakit akibat kerja, pengendalian bahaya di tempat kerja, promosi kesehatan, pengobatan dan rehabilitasi.

Keselamatan pasien rumah sakit adalah suatu sistem yang diterapkan untuk mencegah terjadinya cedera akibat perawatan medis dan kesalahan pengobatan melalui melalui suatu sistem assesment resiko, identifikasi dan pengelolaan faktor risiko, pelaporan dan analisis insiden, 
kemampuan belajar dan tindak lanjut dari incident serta implementasi solusi untuk meminimalkan timbulnya risiko (Dep Kes RI, 2016).

\section{Metode}

Metode ini menggunakan metode kualitatif analisis berlandaskan teori dari buku, jurnal, e-book ataupun sumber informasi lainnya yang memuat informasi dengan pembahasan peran perawat dalam kesehatan dan keselamatan kerja di rumah sakit. Dengan metode ini informasi pembahasan mengenai peran perawat dalam kesehatan dan keselamatan kerja di rumah sakit bisa membuat seorang perawat dapat memahami dan mempelajari bagaimana cara menjaga kesehatan dan keselamatan kerja di rumah sakit. Sumber yang digunakan bersifat subjektif yaitu proses penulisan yang lebih fokus pada landasan teori. Dan melakukan analisis buku dan e-jurnal yang relevan dan berfokus kepada pengaplikasian berfikir kritis dalam mengelola informasi dan komunikasi keperawatan. Sumber yang digunakan adalah sumber yang diterbitkan di 8 tahun terakhir dan referensi akan dicantumkan dibagian daftar pustaka.

\section{Hasil}

Menurut WHO pengertian K3 adalah upaya yang bertujuan untuk meningkatkan dan memelihara derajat kesehatan fisik, mental dan sosial yang setinggi-tingginya bagi pekerja di semua jenis pekerjaan, pencegahan terhadap gangguan kesehatan pekerja yang disebabkan oleh kondisi pekerjaan; perlindungan bagi pekerja dalam pekerjaannya dari risiko akibat faktor yang merugikan kesehatan.

Keselamatan dan kesehatan kerja termasuk salah satu program pemeliharaan yang ada di perusahaan. Pelaksanaan program keselamatan dan kesehatan kerja bagi karyawan sangatlah penting karena bertujuan untuk menciptakan sistem keselamatan dan kesatuan kerja yang nantinya dapat meningkatkan produktivitas kerja karyawan.

K3 adalah upaya yang bertujuan untuk meningkatkan dan memelihara derajat kesehatan fisik, mental dan sosial yang setinggi-tingginya bagi pekerja di semua jenis pekerjaan, pencegahan terhadap gangguan kesehatan pekerja yang disebabkan oleh kondisi pekerjaan; perlindungan bagi pekerja dalam pekerjaannya dari risiko akibat faktor yang merugikan kesehatan. 
Dalam dunia kesehatan sendiri Kesehatan dan Keselamatan Kerja (K3) adalah upaya untuk memberikan jaminan keselamatan dan meningkatkan derajat kesehatan pekerja dengan cara pencegahan kecelakaan dan penyakit akibat kerja (PAK), pengendalian bahaya di tempat kerja, promosi kesehatan, pengobatan, dan rehabilitasi.

Keselamatan pasien (patient safety) adalah permasalahan yang sangat penting dalam setiap pelayanan kesehatan sehingga keselamatan merupakan tanggung jawab dari pemberi jasa pelayanan kesehatan terutama pelayanan keperawatan di setiap unit perawatan baik akut maupun kronis harus berfokus pada keselamatan pasien baik dalam tatanan rumah sakit.

Keperawatan merupakan suatu bentuk pelayanan profesional bersifat humanistik, menggunakan pendekatan holistik, dilakukan berdasarkan ilmu dan kiat keperawatan, berorientasi kepada kebutuhan objektif klien. Praktek keperawatan mengacu pada standar professional keperawatan dan menggunakan etika keperawatan sebagai tuntutan utama. Perawat dituntut untuk selalu melaksanakan asuhan keperawatan yang benar atau rasional (Nursalam, 2007).

Proses asuhan keperawatan merupakan tugas dan kewajiban seorang perawat dari pasien datang sampai pasien pulang, dimulai dengan pengkajian secara menyeluruh, kemudian menegakkan diagnosa keperawatan dari data pengkajian tersebut, serta melaksanakan intervensi, implementasi dan evaluasi keefektifan diagnosa awal yang sudah ditegakkan (Nursalam, 2007).

Perawat sangatlah berperan penting dalam meningkatan kesehatan dan keselamatan kerja di Rumah sakit maka Perawat sebaiknya terus mengembangkan pengetahuan dan keterampilan di bidang manajemen keperawatan khususnya terkait Kesehatan dan Keselamatan Kerja (K3) sehingga pelayanan yang diberikan dapat lebih optimal dan berkualitas tanpa melupakan tingkat kesehatan dan keselamatan bagi pemberi asuhan keperawatan.

Tanggung jawab perawat erat kaitannya dengan tugas-tugas perawat. Tugas perawat secara umum adalah memenuhi kebutuhan dasar serta mengutamakan dan mengoptimalkan keselamatan pasien. Oleh karena itu, asuhan keperawatan sangan menentukan kualitas dari perawat. 
Dengan adanya kepuasan kerja perawat maka diharapkan mereka dapat menjalankan tugasnya dengan baik. Untuk mampu menciptakan tingkat pelayanan yang berkualitas dibutuhkan perawat yang memiliki kualitas pula kemampuan untuk menarik dan menpertahankan tenaga kerja yang berkualitas dan cakap merupakan kebutuhan prasyarat sukses bagi sebuah perusahaan. reputasi perusahaan merupakan modal pokok yang mencerminkan pada kemampuan perusahaan untuk memuaskan ke Keselamatan dan kesehatan kerja (K3) adalah suatu program yang dibuat pekerja maupun pengusaha sebagai upaya mencegah timbulnya kecelakaan akibat kerja dan penyakit serta tindakan antisipatif apabila terjadi kecelakaan dan penyakit kerja. Tujuannya adalah untuk menciptkan tempat keja yang nyaman, dan sehat sehingga dapat menekan serendah mungkin resiko kecelakaan dan penyakit.

Keselamatan kerja dapat mempengaruhi tingkat kepuasan karyawan. Hal tersebut disebabkan apa bila karyawan mendapatkan perlindungan keselamatan kerja dari perusahan, maka karyawan akan merasa aman, sehingga karyawan memiliki kepuasan terhadap perusahaan. Sedangkan Hubungan antara kepuasan kerja dengan kesehatan fisik dan mental. Kajian yang dilakukan korhauser tentang kesehatan mental dan kepuasan kerja adalah untuk semua tingkatan jabatan, persepsi dari tenaga kerja bahwa pekerjaan mereka menuntut penggunaan efektif dari kemampuan mereka berkaitan dengan skor kesehatan.

\section{Pembahasan}

Rumah sakit merupakan sebuah organisasi kesehatan yang sangat bermanfaat guna memberikan pelayanan kesehatan bagi masyarakat, sebagaimana tertera dalam UU RI No 44 pasal 1 (2009, p.2). Setiap tenaga kesehatan yang bekerja dirumah sakit harus bekerja sesuai dengan standar profesi, standar pelayanan rumah sakit, standar prosedur operasional yang berlaku, etika profesi, menghormati hak pasien, dan mengutamakan keselamatan pasien.

Undang-undang No.44 Tahun 2009 tentang Rumah Sakit pasal 7 ayat 1, bahwa "Rumah Sakit harus memenuhi persyaratan lokasi, bangunan, prasarana, sumber daya manusia, kefarmasian, dan peralatan", persyaratan-persyaratan tersebut salah satunya harus memenuhi unsur Keselamatan dan Kesehatan Kerja di dalamnya. Rumah Sakit yang tidak memenuhi persyaratan-persyaratan tersebut tidak diberikan izin mendirikan, dicabut atau tidak diperpanjang izin operasional Rumah Sakit (pasal 17) (MENKES RI, 2009). 
Tenaga kesehatan yang terlibat dalam lingkungan rumah sakit diantaranya tenaga medis dan penunjang medis, tenaga keperawatan, tenaga kefarmasian, tenaga manajemen rumah sakit dan tenaga non kesehatan UU RI No 44 pasal 12-13 (2009, p.11-12). Salah satu pelayanan kesehatan yang diberikan oleh tenaga kesehatan adalah pelayanan keperawatan, Sebagai bagian dari pelayanan kesehatan, maka pelayanan keperawatan yang dilakukan oleh tenaga perawatmemiliki tugas diataranya memberikan asuhan keperawatan (Hidayat, 2011, p.75).

Kecelakaan kerja merupakan kejadian yang tidak terjadi secara kebetulan, melainkan ada sebabnya. Menurut WHO pengertian K3 adalah upaya yang bertujuan untuk meningkatkan dan memelihara derajat kesehatan fisik, mental dan sosial yang setinggitingginya bagi pekerja di semua jenis pekerjaan, pencegahan terhadap gangguan kesehatan pekerja yang disebabkan oleh kondisi pekerjaan; perlindungan bagi pekerja dalam pekerjaannya dari risiko akibat faktor yang merugikan kesehatan.

Dalam dunia kesehatan sendiri Kesehatan dan Keselamatan Kerja (K3) adalah upaya untuk memberikan jaminan keselamatan dan meningkatkan derajat kesehatan pekerja dengan cara pencegahan kecelakaan dan penyakit akibat kerja (PAK), pengendalian bahaya di tempat kerja, promosi kesehatan, pengobatan, dan rehabilitasi.

perawat adalah seseorang (seorang profesional) yang mempunyai kemampuan, tanggung jawab dan kewenangan melaksanakan pelayanan / asuhan keperawatan pada berbagai jenjang pelayanan keperawatan.

Asuhan keperawatan adalah suatu pendekatan untuk pemecahan masalah yang memampukan perawat untuk mengatur dan memberikan asuhan keperawatan. Standar asuhan yang tercantum dalam Standar Praktik Klinis Keperawatan terdiri dari lima fase asuhan keperawatan: 1) Pengkajian; 2) Diagnosa; 3) Perencanaan; 4) Implementasi; dan 5) Evaluasi. Salah satu manfaat dari penerapan asuhan keperawatan yang baik adalah meningkatkan mutu dan kualitas pelayanan dalam bidang keperawatan (Kozier, 2010).

Dan tujuan K3 juga merupakan mencegah, megurangi, bahkan menihilkan resiko penyakit dan kecelakaan akibat kerja (KAK) serta meningkatkan derajat kesehatan para pekerja sehingga produktivitas kerja meningkat. Dalam Undang-Undang Republik Indonesia Nomor 36 Tahun 2009 Tentang Kesehatan, upaya kesehatan kerja ditunjukkan untuk melindungi pekerja 
agar hidup sehat dan terbebas dari gangguan kesehatan serta pengaruh buruk yang diakibatkan oleh pekerjaan sehingga sudah seharusnya pihak pengelola RS menerapkan upaya-upaya K3 di RS. K3 termasuk sebagai salah satu standar pelayanan yang dinilai di dalam akreditasi RS, disamping standar pelayanan lainnya.

Berikut adalah konsep dasar dan jenis-hazard dan resiko keselamatan kerja yang mungkin terjadi di rumah sakit yaitu:

\section{A. Pengertian Kesehatan dan Keselamatan Kerja}

Kesehatan kerja didalam perusahaan merupakan spesialisasi dalam ilmu kesehatan beserta prakteknya dengan mengadakan penilaian kepada faktor-faktor penyebab penyakit dalam lingkungan kerja dan perusahaan melalui pengukuran yang hasilnya dipergunakan untuk dasar tindakan korektif dan bila perlu pencegahan kepada lingkungan tersebut, agar pekerja dan masyarakat sekitar perusahaan terhindar dari bahaya akibat kerja, serta dimungkinkan untuk mengecap derajat kesehatan setinggi-tingginya (Kuswana : 2014).

Sehat merupakan suatu kondisi yang ingin dimiliki oleh setiap individunya. Sehat tidak hanya dalam keadaan fisik, namun juga sehat secara mental dan sehat secara sosial. Tidak hanya meliputi kebebasan dari suatu penyakit, namun juga sehat meliputi keadaan psikis dari seseorang. Sehat pada umumnya mempengaruhi perilaku manusia, begitu pula sebaliknya, perilaku seseorang juga akan dapat mempengaruhi kesehatan orang tersebut.

Keselamatan dan Kesehatan Kerja merupakan suatu permasalahan yang banyak menyita perhatian berbagai organisasi saat ini karena mencakup permasalahan segi perikemanusiaan, biaya dan manfaat ekonomi, aspek hukum, pertanggungjawaban serta citra organisasi itu sendiri.

Keselamatan dan kesehatan kerja (K3) merupakan suatu usaha untuj menciptakan perlindungan dan keamanan dari berbagai resiko kecelakaan dan bahaya baik fisik, mental maupun emosional terhadap pekerja, perusahaan, masyarakat dan lingkungan.

Kesehatan dan Keselamatan Kerja (K3) merupakan salah satu isu penting di dunia kerja saat ini termasuk di lingkungan rumah sakit. Angka kecelakaan kerja di rumah sakit lebih tinggi dibandingkan tempat kerja lainnya dan sebagian besar diakibatkan oleh perilaku yang tidak aman. 
Kecelakaan kerja menjadi salah satu masalah urgen di lingkungan rumah sakit. Hal ini diakibatkan karena rumah sakit merupakan suatu unit pelayanan kesehatan yang memberikan pelayanan pada semua bidang dan jenis penyakit. Oleh sebab itu rumah sakit dituntut untuk dapat menyediakan dan menerapkan suatu upaya agar semua sumber daya manusia yang ada di rumah sakit dapat terlindungi, baik dari penyakit maupun kecelakaan akibat kerja (Ivana, Widjasena \& Jayanti, 2014).

Pemerintah melakukan berbagai upaya untuk mengatasi kecelakaan kerja di rumah sakit, salah satunya dengan dikeluarkannya Undang-Undang Nomor 23 Tahun 1992 dan UndangUndang Nomor 36 Tahun 2009 tentang penerapan Kesehatan dan Keselamatan Kerja di rumah sakit (Kepmenkes RI, 2010).

Hasil penelitian Demak (2013) mengenai analisis penyebab perilaku aman bekerja pada perawat di Rumah Sakit Islam Asshobirin Tangerang Selatan menyatakan bahwa bentuk perilaku tidak aman pada perawat yaitu tidak memakai sarung tangan ketika tindakan menyuntik dan memasang infuse serta tidak menggunakan sepatu yang sesuai. Faktor yang menyebabkan perawat berperilaku tidak aman yaitu sikap negative perawat yang tidak disiplin dalam menggunakan Alat Pelindung Diri (APD) dan Standar Operasional Prosedur (SOP) yang berlaku di RS Islam Asshobirin belum sesuai dengan standar Depkes RI tahun 2006.

Dalam pelayanan kesehatan, para perawat diharapkan juga dapat memberikan pelayanan secara berkualitas. Perawat sebagai tenaga kesehatan yang profesional dan merupakan tenaga kesehatan terbesar yang ada di rumah sakit mempunyai peranan yang sangat penting dalam mewujudkan keselamatan pasien. Perawat berperan mencegah dalam kesalahan medis, mencegah perawatan yang dapat merugikan kesehatan dan menekankan pada pelaporan kejadian yang dapat merugikan pasien. Untuk menjaga patient safety salah satunya dengan menjaga kompetensi perawat yang melakukan tindakan keperawatan mempertahankan posisi ergonomik pasien.

\section{B. Jenis-Jenis Hazard dan Resiko yang Dapat Terjadi di Rumah Sakit}

\section{Hazard Somatik}

Hazard somatik merupakan bahaya yang berasal dari dalam tubuh pekerja yaitu kapasitas kerja dan status kesehatan pekerja. Contohnya seorang pekerja yang buta warna bila 
mengerjakan alat elektronik yang penuh dengan kabel listrik warna-warni, bahaya somatiknya dapat membahayakan dirinya maupun orang lain di sekelilingnya bila ia salah menyambung warna kabel listrik tertentu karena tindakan ini berpotensi menimbulkan kebakaran atau ledakan. Selain itu contoh penyakit yang dapat menjadi bahaya di lapangan kerja seperti hipertensi, diabetes mellitus, obesitas dan asma.

\section{Hazard Perilaku}

Bahaya perilaku kesehatan yaitu bahaya yang terkait dengan perilaku kerja. Contohnya adalah mode rambut panjang di ruang mesin berputar telah mengakibatkan seorang pekerja tertarik dalam mesin dan hancur tubuhnya karena tergiling mesin penggiling. Selain itu kebiasaan seseorang yang merokok di tempat kerja juga dapat membahayakan keselamatannya.

\section{Hazard Lingkungan Kerja}

Hazard lingkungan kerja (environmental hazard) dapat berupa faktor fisik, kimia, dan biologik.Faktor fisik, kimia dan biologik yang berada ditempat kerja berpotensi menimbulkan gangguan kesehatan bila kadarnya atau intensitas pajanannya tinggi melampaui toleransi kemampuan tubuh pekerja. Hazard di lingkungan kerja antara lain:

a. Bahaya fisik, berpotensi menimbulkan terjadinya Penyakit Akibat Kerja (PAK). Jenisjenis bahaya yang termasuk dalam golongan fisik serta pekerja berisiko terpajan antara lain adalah sebagai berikut:

1) Bahaya mekanik Yang termasuk ke dalamm bahaya mekanik antara lain terbentur, tertusuk, tersayat, terjepit, tertekan, terjatuh, terpeleset, terkilir, tertabrak, terbakar, terkena serpihan ledakan, tersiram, dan tertelan.

2) Bising, Berasal dari bunyi atau suara yang tidak dikehendaki dan dapat menganggu kesehatan, kenyamanan, serta dapat menyebabkan gangguan pendengaran (ketulian).

3) Getar atau Vibration Getar dapat menimbulkan gangguan pendengaran, muskoloskeletal, keseimbagan, white finger dan hematuri mikroskopik akibat kerusakan saraf tepi dan jarinagn pembuluh darah.

4) Suhu ekstrem panas Merupakan tekanan panas yang melebihi kemampuan adaptasi, dapat menimbulkan heat cramp, heat exhaustion dan heat stroke, dan kelainan kulit. contoh peralatan kerja mengeluarkan suhu ekstrem panas adalah tempat pembakaran (furnace), dapur atau tempat pemanasan (boiler). 
5) Suhu ekstrem dingin Pajanan suhu ekstrem dingin dilingkungan kerja dapat menimbulkan frostbite (kerusakan kulit dan sel akibat suhu dingin ekstrem) yang ditandai dengan bagian tubuh mati rasa diujung jari atau daun telinga, serta gejala hipotermia yaitu suhu tubuh di bawah $350 \mathrm{o}$ dan dapat mengancam jiwa. Pekerja yang berisiko seperti penyelam.

6) Cahaya Cahaya yang kurang atau terlalu terang dapat merusak mata.

7) Radiasi Pengion Berasal dari sinar alfa, sinar beta, sinar gamma atau sinar-X, pekerja yang berisiko yaitu radiografer di bagian radiologi di suatu klinik atau rumah sakit.

b. Bahaya Kimia, berpotensi menimbulkan gangguan kesehatan yang sangat luas dari yang ringan seperti bersin-bersin, kulit gatal sampai yang berat seperti kelainan organ hati dan saraf, gagal ginjal atau cacat fungsi paru. Didalam bidang kesehatan, ini biasanya terjadi pada tenaga kesehatan di bidang Apoteker.

c. Bahaya Biologik, berpotensi menimbulkan penyakit infeksi akibat kerja (PAK), dari penyakit flu biasa sampai SARS bahkan HIV/AIDS bagi pekerja kesehatan.

\section{Hazard Ergonomik}

Hazard ergonomik yang dimaksud terkait dengan kondisi pekerjaan yang dilakukan serta peralatan kerja yang digunakan oleh pekerja termasuk work station. Contoh pekerja yang mengalami hazard ergonomik adalah pengemudi, penjahit, perawat.

Ergonomic merupakan ilmu yang penerapannya berusaha untuk menyerasikan pekerjaan dan lingkungan terhadap orang atau sebaliknya, dengan tujuan tercapainya produktivitas dan efisiensi setinggi-tingginya melalui pemanfaatan factor manusia seoptimal mungkin. Oleh sebab itu perawat harus bisa mempertahankan keselamatan pasien dan perawat, perawat harus mempertahankan posisi ergonomik pada pasien dan dirinya sendiri disaat pasien sedang konsultasi.

\section{Hazard Pengorganisasian Pekerjaan dan Budaya Kerja}

Contohnya adalah faktor stress kerja berupa beban kerja berlebih atau pembagian pekerjaan yang tidak proporsional, budaya kerja sampai larut malam dan mengabaikan kehidupan sosial pekerja. 
Kesehatan dan Keselamatan Kerja (K3) merupakan upaya untuk mengendalikan, meminimalisasi dan meniadakannya bahaya di rumah sakit dapat dilakukan melalui sistem K3RS. Peningkatan kesehatan di rumah sakit dalam melakukan kesehatan dan keselamatan kerja bisa dilakukan oleh perawat sesuai dengan asuhan keperawatan yang sudah di tetapkan. Selain itu perawat juga bisa melakukan pendidikan dan pelatihan dengan berbagai metode dan menggunakan media yang intraktif guna untuk menambah wawasan pengetahuan pasien dan pengunjung rumah sakit terutama keluarga.

\section{Penutup}

Kesehatan dan keselamatan kerja merupakan aspek yang penting dalam usaha meningkatkan kesejahteraan karyawan. Apabila tingkat keselamatan kerja tinggi, maka kecelakaan yang menyebabkan sakit, cacat, dan kematian dapat ditekan sekecil mungkin. Kesehatan dan Keselamatan Kerja (K3) merupakan salah satu isu penting di dunia kerja saat ini termasuk di lingkungan rumah sakit. Angka kecelakaan kerja di rumah sakit lebih tinggi dibandingkan tempat kerja lainnya dan sebagian besar diakibatkan oleh perilaku yang tidak aman. Rumah sakit merupakan perusahaan yang memiliki kegiatan operasional jasa pelayanan kesehatan bagi masyarakat dimana sangat membutuhkan tenaga kerja yang berkualitas, untuk mencapai tujuan yang diharapkan oleh pihak rumah sakit maka dapat dilakukan dengan cara membentuk suatu kepuasan kerja pada perawatnya.

Setiap tenaga kesehatan yang bekerja dirumah sakit harus bekerja sesuai dengan standar profesi, standar pelayanan rumah sakit, standar prosedur operasional yang berlaku, etika profesi, menghormati hak pasien, dan mengutamakan keselamatan pasien sesuai dengan asuhan keperawatan.

Seorang tenaga kesehatan atau perawat harus mengetahui tiga komponen K3 yaitu kapasitas kerja, beban kerja dan lingkungan kerja. Dan seorang perawat juga harus mengetahui Komitmen dan Kebijakan Komitmen diwujudkan dalam bentuk kebijakan (policy) tertulis, jelas dan mudah dimengerti serta diketahui oleh seluruh karyawan RS, agar tenaga kesehatan khususnya perawat terhindar dari risiko bahaya kerja di rumah sakit. 


\section{Daftar Pustaka}

Firawati. (2012). Pelaksanaan Program Keselamatan Pasien di RSUD Solok. Jurnal Kesehatan Masyarakat,6(2).

Ivana, A.(2014, Januari). Analisa Komitmen Manajemen Rumah Sakit (RS) Terhadap Keselamatan Dan Kesehatan Kerja (K3) Pada RS Prima Medika Pemalang. Semarang. JURNAL KESEHATAN MASYARAKAT (e-Journal),2(1), 35-41

Nurhidayanti, D. (2017, Februari). ENGARUH PELAKSANAAN KESELAMATAN DAN KESEHATAN KERJA (K3) TERHADAP KEPUASAN KERJA PERAWAT. Jurusan Ilmu Administrasi, 4(1), 1-10.

Putri Wulandini. S., T. K. (2016, Oktober). FAKTOR-FAKTOR YANG BERHUBUNGAN DENGAN PENDOKUMENTASIAN ASUHAN KEPERAWATAN DI RUMAH SAKIT JIWA. NERS JURNAL KEPERAWATAN, 12(2), 131-142.

Riska Nazirah, Y. (2017). PERILAKU PERAWAT DALAM PENERAPAN MANAJEMEN KESEHATAN DAN KESELAMATAN KERJA (K3) DI ACEH. Idea Nursing Journal, $8(2), 1-6$.

Rivai, F., Sidin, A. I. \& Kartika, I. (2016). Faktor yang Berhubungan dengan Implementasi Keselamatan Pasien di RSUD Ajjappannge Soppeng Tahun 2015. Jurnal Kebijakan Kesehatan Indonesia,5(4), 152-157.

Salawati, L. (2014, Desember). ANALISIS TINDAKAN KESELAMATAN DAN KESEHATAN KERJA PERAWAT DALAM PENGENDALIAN INFEKSI NOSOKOMIAL DI RUANG ICU RSUD DR. ZAINOEL ABIDIN BANDA ACEH. JURNAL KEDOKTERAN SYIAH KUALA,14(3), 128-134.

Salmawati, L (2015, Maret). HUBUNGAN PENERAPAN SISTEM MANAJEMEN KESELAMATAN DAN KESEHATAN KERJA DENGAN MOTIVASI KERJA DAN STRES KERJA PADA PERAWAT DI RUMAH SAKIT UMUM ANUTAPURA PALU. JURNAL MANAJEMEN PELAYANAN KESEHATAN, 18(1), 4-6. 
Samuel Dwi Krisna Triyono, Y. K. (2017). KONSEP SEHAT DAN SAKIT PADA INDIVIDU DENGAN UROLITHIASIS (KENCING BATU) DI KABUPATEN KLUNGKUNG, BALI. Jurnal Psikologi Udayana, 4(2), 263-276.

Sehat, P. P. (2015, Juni). Zaraz Obella Nur Adliyani. Majority, 4(7), 109-114.

Simamora, R. H. (2011). ROLE CONFLICT OF NURSE RELATIONSHIP WITH PERFORMANCE IN THE EMERGENCY UNIT OF HOSPITALS RSD DR. SOEBANDI JEMBER. The Malaysian Journal of Nursing, 3(2), 23-32.

Soputan, G. E. (2019). MANAJEMEN RISIKO KESEHATAN DAN KESELAMATAN KERJA (K3) (Study Kasus Pada Pembangunan Gedung SMA Eben Haezar). Jurnal Ilmiah Media Engineering, 4(4), 229-238.

Yuwono, Rio, dan Ferida Yuamita. (2015). Analisa Faktor K3 Dan Ergonomi Terhadap Fasilitas Pusat Kesehatan Universitas Untuk Mengukur Kepuasan Pasien. Jurnal Ilmiah Teknik Industri, 14(1), 1-12. 